\title{
Mothers' Knowledge of Childhood Neurodevelopmental Disorders: Indian Perspective
}

\author{
Kathyayani B. V. \\ ${ }^{1}$ College of Nursing, National Institute of Mental Health and Neuro \\ Sciences, Bengaluru, Karnataka, India
}

J Neurosci Rural Pract:2021;12:165-170

\begin{abstract}
Address for correspondence Rajalakshmi Ramu, PhD Scholar, Department of Nursing and Clinical Instructor, College of Nursing, National Institute of Mental Health and Neuro Sciences, Bengaluru, Karnataka 560011, India

(e-mail: radhikanmj@gmail.com).
\end{abstract}

Abstract

Keywords
- childhood
neurodevelopmental
disorders
- knowledge
- mothers
- children younger than

5 years

Objectives This study aims to assess the knowledge of childhood neurodevelopmental disorders (CNDDs) among mothers of children younger than 5 years and to promote awareness through health education to promote early identification.

Methods Quantitative approach, a descriptive survey in nature research design, was used. A total of 173 mothers who contented the inclusion conditions were chosen as sample on the basis of purposive sampling. The research study was done at the selected Primary Health Centre, Bengaluru, Karnataka. The tabulations were measured and construed based on the objectives of the study by using descriptive and inferential statistics.

Results The findings showed that most of the mothers have insufficient knowledge (mean and standard deviation: $3.02 \pm 2.75$ ) and there is no substantial relationship found between mothers' knowledge on CNDD and their demographic variables except their occupation and majority of the mothers communicated that they needed further facts toward CNDD.

Conclusion The government and nongovernmental organizations can take initiations to conduct health education programs toward childhood developmental delays and disorders for the general public including mothers and community health workers.

\section{Introduction}

The World Health Organization estimates that about $10 \%$ of the world's population has some form of disability. Numerical measurements from various bases indicated that in the country, $3.8 \%$ of the total population have some form of disability. ${ }^{1}$ A significant percentage of children have an identifiable (neurodevelopmental disorders [NDD]), high prevalence of childhood neurodevelopmental disorders (CNDDs) found in India. ${ }^{2}$ Currently, CNDDs stand by mounting at the global level. "Developmental disorders" are set of circumstances resulting from impairments that affect a child's bodily, educational, and behavioral activity, further the previous researchers also said that most of the childhood developmental disorders are the precursor for the adolescent and adulthood mental illness. ${ }^{3}$ Kids with developmental delays and incapacities are at more hazard of having suboptimal physical health, learning accomplishment, mental health, and happiness. ${ }^{1}$ As India is having a lot of stigma toward childhood mental illness and most of them having poor knowledge and understanding on mental illness, to improve the knowledge and to reduce the stigma, here is an augmented necessity for community learning programs

(c) 2021. Association for Helping Neurosurgical Sick People.

This is an open access article published by Thieme under the terms of the Creative Commons Attribution-NonDerivative-NonCommercial-License, permitting copying and reproduction so long as the original work is given appropriate credit. Contents may not be used for commercial purposes, or adapted, remixed, transformed or built upon. (https://creativecommons.org/licenses/by-nc-nd/4.0/)

Thieme Medical and Scientific Publishers Pvt. Ltd., A-12, 2nd Floor, Sector 2, Noida-201301 UP, India 
about attention of kids with NDDs such as autism. ${ }^{4}$ Early identification and interventions may reduce the disability, burden on the families, and as a whole, it reduces the burden on the society. Mother's knowledge may influence the early identification process. ${ }^{5,6}$ Bakare et al in 2016 did an experimental study among 2,893 mothers of children younger than 5 years at Nigeria and found that mothers' knowledge was poor before the health education toward CNDD. ${ }^{6}$ Parents having children with NDDs often face more complex psychosocial consequences, during this critical period, mother's knowledge is important to provide comprehensive care to the child and other family members. ${ }^{7}$ However, the knowledge and awareness about CNDD are very poor among the general public including mothers of children younger than 5 years and that need to be improved. ${ }^{6,8}$ Further, the parents' and health care professionals' knowledge and perception will influence the early identification of the CNDD, ${ }^{7,9}$ but CNDDs are not screened regularly in India, ${ }^{7}$ to do that, previous researchers had recommended that family member, health care workers, and community need to be educated about developmental disorders and disabilities. ${ }^{10}$ With this background present, researchers planned to identify the mothers' knowledge on NDD, to educate them through possible health education program to accelerate the early identification and intervention to reduce the disability among the children.

\section{Methods}

This was a cross-sectional descriptive survey to assess the knowledge on CNDDs among mothers at selected primary health center in Bengaluru. The aim of this present study envisioned to promote awareness through health education to accelerate early identification of CNDDs. The study followed quantitative approach with the design of descriptive cross-sectional survey in nature. The study population was mothers. Sample chosen for the present study was mothers of children younger than 5 years and the sample size was 173 mothers. Inclusion criteria for the present study were mothers having children younger than 5 years and those who visited the immunization clinic and outpatient department of selected primary health center during the data collection period. Exclusion criteria were mothers who were not having children younger than 5 years and those who were not agreeable to contribute in the research study. The authors have applied purposive sampling technique to chosen the study subjects.

Materials and methods used for the current study were sociodemographic questionnaire to obtain basic demographic information such as age, educational status, religion, and occupation of the mothers, and general awareness on CNDD and child's developmental information. Knowledge and awareness about childhood neurodevelopmental disorders (KACNDD) questionnaire ${ }^{6}$ to assess the mother's knowledge about CNDD, which has two main domains, domain 1 contains six items that addressed symptoms associated with CNDDs and domain 2 contains eight items that addressed possible etiologies of CNDDs. The score ranges from 0 to 14 . Higher the score indicates higher level of knowledge. The
KACNDD questionnaire has good internal consistency with Cronbach alpha of 0.84 .

\section{Data Collection}

The researcher obtained data from study subjects during the month of December 2019 after getting permission from concerned authorities. After selecting the study subjects, informed written consent was obtained from each subjects, and data were collected through an interview method at the immunization clinic and OPD at selected Primary Health Centre, Bengaluru. Averagely, it took 10 to 15 minutes for the data collection per individual.

\section{Data Analyses}

One hundred and eighty-two eligible mothers were interviewed during the data collection period for the present study. Out of that, nine mothers were not interested to give the detailed information about them and their children, and the sample population size calculated for the present study was 173 . Interpretation of data was made to fulfill the objectives by using Software Packages for Social Sciences (SPSS) 25.0.

\section{Results}

- Table 1 reveals the sociodemographic variables of the mothers. Majority of the mothers, $n=105$ (61\%) were in the group of below 30 years, and 68 (39\%) were in the group of above 30 years of age. Seventy-six (44\%) of them studied up to PUC, 64 (37\%) of them studied primary education, 23 (13\%) completed graduation, and only 10 (6\%) were not studied anything. Religion wise, 99 (57\%) of the mothers belong to the Hindu category, 69 (40\%) were Muslims, and only 5 (3\%) belong to Christians. Based on the study subjects' occupation, they were divided into homemakers, 139 (80\%) and others 34 (20\%).

- Table 2 reveals that majority, $n=158$ (92\%), of the mothers said that their children are having normal development, and only 15 (8\%) mothers said that their children are having some developmental issues. Majority, 168 (97\%), of the mothers said that their children have normal milestones, but only 5 (3\%) mothers said that their children are having delayed developmental milestones. Majority, 152 (87\%), of the mothers said that their children were not born with prematurity and at the same time, 21 (13\%) mothers said that their children were born with prematurity. Majority, $n=158$ (90\%), of the mothers participated in the study were not aware about CNDD, and only 15 (10\%) were said they knows about CNDD. Majority, 155 (90\%), of the study subjects said that they did not receive any of the information regarding CNDD from the health professionals, and only 18 (10\%) mothers said that they received some information from the health care professionals. Finally, majority, 130 (75\%), of the mothers said that they want further information about CNDD, but 43 (25\%) mothers said that they do not want any more information about CNDD.

- Table 3 reveals that most of the mothers have given wrong answers during the survey and had poor knowledge. 
Table 1 Assessment of sociodemographic details of the study subject (mothers) $(n=173)$

\begin{tabular}{|c|c|c|c|c|}
\hline S. No. & Sociodemographic variables & Category & $F$ & Percentage \\
\hline \multirow[t]{2}{*}{1} & \multirow[t]{2}{*}{ Age } & $<30$ & 105 & 61 \\
\hline & & $>30$ & 68 & 39 \\
\hline \multirow[t]{4}{*}{2} & \multirow[t]{4}{*}{ Education } & Illiterate & 10 & 6 \\
\hline & & Primary & 64 & 37 \\
\hline & & PUC & 76 & 44 \\
\hline & & Graduates & 23 & 13 \\
\hline \multirow[t]{3}{*}{3} & \multirow[t]{3}{*}{ Religion } & Hindu & 99 & 57 \\
\hline & & Muslims & 69 & 40 \\
\hline & & Christians & 05 & 03 \\
\hline \multirow[t]{2}{*}{4} & \multirow[t]{2}{*}{ Occupation } & Homemakers & 139 & 80 \\
\hline & & Others & 34 & 20 \\
\hline
\end{tabular}

Table 2 Description of the study subjects' general awareness about CNDD and development of children younger than 5 years $(n=173)$

\begin{tabular}{|l|l|l|l|}
\hline S. No. & Items & Response & Frequency \\
\hline 1 & Does your child have normal development? & Yes & $158(92 \%)$ \\
\cline { 2 - 3 } & & No & $15(8 \%)$ \\
\hline 2 & Does your child born with prematurity? & Yes & $21(13 \%)$ \\
\cline { 3 - 4 } & & No & $152(87 \%)$ \\
\hline 3 & Does your child have delayed milestones? & Yes & $5(3 \%)$ \\
\cline { 2 - 4 } & & No & $168(97 \%)$ \\
\hline 4 & Does your child have any developmental issues? & Yes & $7(5 \%)$ \\
\cline { 2 - 4 } & & No & $166(95 \%)$ \\
\hline 5 & Do you know what is CNDD? & Yes & $15(10 \%)$ \\
\cline { 2 - 4 } & & No & $158(90 \%)$ \\
\hline 6 & Have you received any information about CNDD from health & Yes & $18(10 \%)$ \\
\cline { 2 - 4 } & Drofessionals? & No & $155(90 \%)$ \\
\hline 7 & Do you want further information (or) to know more about CNDD? & Yes & $130(75 \%)$ \\
\cline { 3 - 4 } & & No & $43(25 \%)$ \\
\hline
\end{tabular}

Abbreviation: CNDD, childhood neurodevelopmental disorder.

The mean score and standard deviation for the knowledge about symptom and etiology of CNDD for the total study subjects $(n=173)$ are $1.60 \pm 1.59$ and $1.42 \pm 1.53$, respectively. This shows that the participants had very poor knowledge and awareness about CNDDs. The overall knowledge score and the standard deviation was $3.02 \pm$ 2.75. The study found that most of the mothers required supplementary details toward CNDD.

- Table 4 reveals the association between study subjects' selected sociodemographic variables and knowledge scores, except the study subjects' occupation (" $t$-value = 4.757 " and " $p<0.001$ "), and no other sociodemographic variables have significant association with study subjects' knowledge score.

\section{Discussion}

Childhood period and children's development are an important aspect of parenting. Health care system is currently focusing childhood illness and its early identification and intervention. ${ }^{11,12}$ Every parents should know about CNDDs at the most early to prevent disability in their children and evidence-based researches recommended to educate the parents about NDD. ${ }^{13}$ Hence, in this study, we tried to identify the knowledge and awareness about NDD among mothers who are having children younger than 5 years. Based on the results, we could identify that study subjects are not known that the "CNDD is a disorder of brain development," most of the time which will occur in childhood period, it may affect a child's "muscular region," "cognition," and child's "physical/facial" appearance. Even they do not know that the "NDDs" may result from "social deprivation," "genetic disorder," "immune dysfunction," "childhood infectious diseases," “inadequate/abnormal nutrition," "trauma," and "metabolic disorder." Similar findings were reported by other researchers in different studies. ${ }^{5,8,13}$ Based on the study subjects' knowledge score, we understood that mothers of children younger than 5 years are having 
Table 3 Description of the study subjects' mean knowledge score

\begin{tabular}{|c|c|c|c|c|c|}
\hline S. No. & Items & Answer & $F$ & $\begin{array}{l}\text { Domain } \\
\text { (mean } \pm \text { SD) } \\
\text { score }\end{array}$ & $\begin{array}{l}\text { Total mean } \pm \\
\text { SD score }\end{array}$ \\
\hline & Domain 1: clinical symptoms & & & & $3.02 \pm 2.75$ \\
\hline \multirow[t]{2}{*}{1} & \multirow{2}{*}{$\begin{array}{l}\text { A neurodevelopmental disorder is a disorder of brain } \\
\text { development }\end{array}$} & Wrong (0) & 135 & \multirow[t]{12}{*}{$1.60 \pm 1.59$} & \\
\hline & & Correct (1) & 38 & & \\
\hline \multirow[t]{2}{*}{2} & \multirow[t]{2}{*}{ A neurodevelopmental disorder occurs in childhood } & Wrong (0) & 66 & & \\
\hline & & Correct (1) & 107 & & \\
\hline \multirow[t]{2}{*}{3} & \multirow{2}{*}{$\begin{array}{l}\text { A neurodevelopmental disorder may affect a child's muscle } \\
\text { activities such as crawling/walking }\end{array}$} & Wrong (0) & 135 & & \\
\hline & & Correct (1) & 37 & & \\
\hline \multirow[t]{2}{*}{4} & \multirow{2}{*}{$\begin{array}{l}\text { A neurodevelopmental disorder may affect a child's } \\
\text { communication, speech and language }\end{array}$} & Wrong (0) & 129 & & \\
\hline & & Correct (1) & 44 & & \\
\hline \multirow[t]{2}{*}{5} & \multirow{2}{*}{$\begin{array}{l}\text { A neurodevelopmental disorder may affect the emotion and } \\
\text { cognition of a child }\end{array}$} & Wrong (0) & 150 & & \\
\hline & & Correct (1) & 23 & & \\
\hline \multirow[t]{3}{*}{6} & \multirow{2}{*}{$\begin{array}{l}\text { A neurodevelopmental disorder may affect a child's physical/ } \\
\text { facial appearance }\end{array}$} & Wrong (0) & 144 & & \\
\hline & & Correct (1) & 29 & & \\
\hline & Domain 2: etiology & & & & \\
\hline \multirow[t]{2}{*}{7} & \multirow{2}{*}{$\begin{array}{l}\text { A neurodevelopmental disorder may result from social } \\
\text { deprivation }\end{array}$} & Wrong (0) & 159 & \multirow[t]{16}{*}{$3.02 \pm 2.75$} & \\
\hline & & Correct (1) & 14 & & \\
\hline \multirow[t]{2}{*}{8} & \multirow{2}{*}{$\begin{array}{l}\text { A neurodevelopmental disorder may result from a genetic } \\
\text { disorder }\end{array}$} & Wrong (0) & 130 & & \\
\hline & & Correct (1) & 43 & & \\
\hline \multirow[t]{2}{*}{9} & \multirow{2}{*}{$\begin{array}{l}\text { A neurodevelopmental disorder may result from immune } \\
\text { dysfunction }\end{array}$} & Wrong $(0)$ & 161 & & \\
\hline & & Correct (1) & 12 & & \\
\hline \multirow[t]{2}{*}{10} & \multirow{2}{*}{$\begin{array}{l}\text { A neurodevelopmental disorder may result from childhood } \\
\text { infectious diseases }\end{array}$} & Wrong (0) & 114 & & \\
\hline & & Correct (1) & 59 & & \\
\hline \multirow[t]{2}{*}{11} & \multirow{2}{*}{$\begin{array}{l}\text { A neurodevelopmental disorder may result from inadequate/ } \\
\text { abnormal nutrition }\end{array}$} & Wrong (0) & 118 & & \\
\hline & & Correct (1) & 55 & & \\
\hline \multirow[t]{2}{*}{12} & \multirow[t]{2}{*}{ A neurodevelopmental disorder may result from trauma } & Wrong (0) & 141 & & \\
\hline & & Correct (1) & 32 & & \\
\hline \multirow[t]{2}{*}{13} & \multirow{2}{*}{$\begin{array}{l}\text { A neurodevelopmental disorder may result from metabolic } \\
\text { disorder }\end{array}$} & Wrong $(0)$ & 158 & & \\
\hline & & Correct (1) & 15 & & \\
\hline \multirow[t]{2}{*}{14} & \multirow{2}{*}{$\begin{array}{l}\text { A developmental Delay may result from Toxic and } \\
\text { Environmental factors }\end{array}$} & Wrong (0) & 158 & & \\
\hline & & Correct (1) & 15 & & \\
\hline
\end{tabular}

lesser knowledge toward CNDD. While we did item analysis we found, most of the study subjects had given wrong answers about CNDD, it shows that they are having inadequate knowledge in this arena. This poor knowledge and understanding about CNDD may be due to the mother's average educational level, that is, most of them completed preuniversity degree only. Further, most of the study subjects were not going to any kind of job and they were being as homemakers. From the earlier said results and discussions, we understood that education and occupation might be the important factors which will influence the knowledge of the mothers. Hence, it is very much worthwhile to educate the mothers and family members to monitor their children's development to accelerate early identification and intervention. ${ }^{14}$ Parent-mediated intervention seems to be effective to modify the children's behavior. To do that, parental education is important. ${ }^{15,16}$ As per the researchers' knowledge, this is the first study in India. It is the need for an hour to provide information to the mothers about CNDD. Additionally, information booklets about CNDD were prepared by the researchers and distributed to the mothers. We assumed this information booklet may enhance the mother's knowledge about the CNDD. Subsequently, they may express their concerns toward the child's developmental issues as early as possible.

\section{Implications to Nursing}

Based on findings, the nursing professionals can design and develop interventional strategies. The study result will be useful to train and equip the nurses to provide health 
Table 4 Association of selected study subjects' sociodemographic variables and their knowledge score

\begin{tabular}{|c|c|c|c|c|c|c|c|c|c|}
\hline $\begin{array}{l}\text { S. } \\
\text { No. }\end{array}$ & Knowledge score: domains & $\begin{array}{l}\text { Sociodemographic } \\
\text { variables }\end{array}$ & $\mathrm{F}$ & Mean & $\begin{array}{l}\text { Standard } \\
\text { deviation }\end{array}$ & $\begin{array}{l}\text { Standard } \\
\text { error, mean }\end{array}$ & $\begin{array}{l}t / F \\
\text { value }\end{array}$ & df & $p$-Value \\
\hline \multirow[t]{5}{*}{1} & \multirow{3}{*}{$\begin{array}{l}\text { Clinical symptom knowledge } \\
\text { score }\end{array}$} & Religion & & & & & & & \\
\hline & & Hindus & 99 & 1.5556 & 1.48614 & 0.14936 & \multirow[t]{2}{*}{0.489} & \multirow[t]{2}{*}{171} & \multirow[t]{2}{*}{0.625} \\
\hline & & Non-Hindus & 74 & 1.6757 & 1.73685 & 0.20191 & & & \\
\hline & \multirow[t]{2}{*}{ Etiology knowledge score } & Hindus & 99 & 1.4242 & 1.40764 & 0.14147 & \multirow[t]{2}{*}{0.080} & \multirow[t]{2}{*}{171} & \multirow[t]{2}{*}{0.936} \\
\hline & & Non-Hindus & 74 & 1.4054 & 1.67920 & 0.19520 & & & \\
\hline \multirow[t]{5}{*}{2} & \multirow{3}{*}{$\begin{array}{l}\text { Clinical symptom knowledge } \\
\text { score }\end{array}$} & Occupation & & & & & & & \\
\hline & & Homemaker & 139 & 1.3381 & 1.47223 & 0.12487 & \multirow[t]{2}{*}{4.757} & \multirow[t]{2}{*}{171} & \multirow[t]{2}{*}{$<0.001^{\mathrm{a}}$} \\
\hline & & Others & 34 & 2.7059 & 1.62424 & 0.27855 & & & \\
\hline & \multirow[t]{2}{*}{ Etiology knowledge score } & Homemaker & 139 & 1.3453 & 1.47792 & 0.12536 & \multirow[t]{2}{*}{1.238} & \multirow[t]{2}{*}{171} & \multirow[t]{2}{*}{0.218} \\
\hline & & Others & 34 & 1.7059 & 1.69722 & 0.29107 & & & \\
\hline \multirow[t]{5}{*}{3} & \multirow{3}{*}{$\begin{array}{l}\text { Clinical symptom knowledge } \\
\text { score }\end{array}$} & Family type & & & & & & & \\
\hline & & Nuclear & 127 & 1.6850 & 1.60703 & 0.14260 & \multirow[t]{2}{*}{1.071} & \multirow[t]{2}{*}{171} & \multirow[t]{2}{*}{0.286} \\
\hline & & Others & 46 & 1.3913 & 1.55604 & 0.22943 & & & \\
\hline & \multirow[t]{2}{*}{ Etiology knowledge score } & Nuclear & 127 & 1.4331 & 1.57153 & 0.13945 & \multirow[t]{2}{*}{0.241} & \multirow[t]{2}{*}{171} & \multirow[t]{2}{*}{0.810} \\
\hline & & Others & 46 & 1.3696 & 1.40410 & 0.20702 & & & \\
\hline 4 & Total knowledge score & Education & 173 & 3.02 & 2.749 & 0.209 & $\begin{array}{l}\text { F-value } \\
1.938\end{array}$ & 3 & 0.125 \\
\hline
\end{tabular}

aSignificant level $<0.05$.

education to mothers. Nurse administrator can conduct refresher courses and workshops for nurses. Community health nurse can conduct health education programs to the mothers of children younger than 5 years. By pursuing the research in this arena, nurse researchers could contribute their enriched knowledge toward the early intervention of CNDDs.

\section{Recommendations}

Similar study could be replicated on a large sample. An experimental research to measure the efficacy of health education toward familiarity of knowledge, screening, and early identification of the CNDDs may be conducted. Effectiveness of information booklet on the level of knowledge regarding CNDDs and its management may be conducted.

\section{Limitations}

The study was conducted with small sample size, thus the generalization of these findings was limited. Subjects were from various educational category, thus it reduced the homogeneity of the study subjects. There is a dearth of studies that had addressed the issues of knowledge and awareness about CNDD. Most of the previous studies had focused specifically on "autism spectrum disorder," "specific learning disability," and "intellectual disability disorder." Hence, the authors found limitation in availing the studies to compare our present findings.

\section{Strength of the Study}

As per the researchers' awareness, this study was conducted for the first time in South India.

\section{Conclusion}

It is concluded that the researchers found that mothers of children younger than 5 years are not having adequate knowledge on CNDDs. The government and nongovernmental organizations can take initiations to implement the health programs toward childhood developmental delays and disorders for the general public including mothers of children younger than 5 years and health care professionals. The information, education, and communication materials like information booklets can be prepared by the researchers and distributed to the mothers. The researchers recommend that the educational system should be equipped to prevent CNDD and early identification of CNDD may promote the early intervention and reduce the disability.

\section{Ethical Approval}

The authors obtained ethical clearance from research review committee of College of Nursing, NIMHANS. The researchers collected data after getting permission from the authorities of the selected Primary Health Centre, Bengaluru. The researchers also obtained individual consent from the study participants.

\section{Funding}

None. 


\section{Conflict of Interest}

None declared.

\section{Acknowledgment}

The authors are thankful to the organizational authorities and study subjects.

\section{References}

1 World Health Council Resolution on Disability including Prevention, Treatment and Rehabilitation. Available at: http:// www.who.int/disitations/publications/other/wha5823/en/. Accessed June 18, 2020

2 Dalwai S, Ahmed S, Udani V, Mundkur N, Kamath SS, Nair MKC. Consensus report of the Indian Academy of Pediatrics on the assessment and treatment of autism spectrum disorder. Pediatrics of India 2017;54(5):385-393

3 Arora NK, Nair MKC, Gulati S, et al. Neurodevelopmental disorders in children aged 2-9 years: population-based burden estimates across five regions in India. PLoS Med 2018; 15(7):e1002615

4 WHO. Developmental problems in childhood: prevention, early identification, assessment and intervention in low- and middle-income countries. WHO. Available at: https://www.who. int/maternal_child_adolescent/documents/development_difficulties_early_childhood/en/. Accessed June 18, 2020

5 Abirami B, Jayabharathi B, Jyoti D. Jagadish S. Assessment on level of knowledge regarding iron deficiency anemia during pregnancy among antenatal mothers at SRM General Hospital. Int J Nurs Educ 2018;10(4):1-6

6 Bakare MO, Bello-Mojeed MA, Munir K, Ogun OC, Eaton J, Tunde-Ayinmode MF. Effect of Educational Intervention on Knowledge and Awareness about Childhood Neurodevelopmental Disorders among Mothers attending Immunization
Clinics in Lagos State, Nigeria. Neurology, Brain and Psychiatry. 2016;2, (1):1-8

7 Alsehemi MA, Abousaadah MM, Sairafi RA, Jan MM. Public awareness of autism spectrum disorder. Neurosciences (Riyadh) 2017;22(3):213-215

8 Srinath S, Chaudhary J, Bhide AV. Narayanan HS, Sivaprakash. Descriptive study of childhood autism. Nimhans J 1989;7(1): 77-81

9 Samms-Vaughan ME. The status of early identification and early intervention in autism spectrum disorders in lowerand middle-income countries. Int J Speech Lang Pathol 2014; 16(1):30-35

10 Newton CR. Neurodevelopmental disorders in low-and middleincome countries. Dev Med Child Neurol 2012;54(12): 1072-1072

11 Rajaratnam JK, Marcus JR, Flaxman AD, et al. Neonatal, postneonatal, childhood, and under-5 mortality for 187 countries, 19702010: a systematic analysis of progress towards Millennium Development Goal 4. Lancet 2010;375(9730) :1988-2008

12 Dawson G. Prevention of early behavioral intervention, brain plasticity and autism spectrum disorder. Dev Psychol 2008; 20(3):775-803

13 Bishnu Prasad M, Yaw Y, Jingi F. Questionnaire study of parental awareness of childhood neurodevelopmental disorder. Int J Pediatr Res 2019;5(2):1-7

14 Majnemer A. Benefits of early intervention for children with developmental disabilities. Semin Pediatr Neurol 1998; 5(1):62-69

15 Mukherjee SB, Aneja S, Krishnamurthy V, Srinivasan R. Incorporating growth assessment and consulting young children. Pediatrics of India. 2014;51(8):627-635

16 Imran N, Chaudry MR, Azeem MW, Bhatti MR, Choudhary ZI, Cheema MA. A survey of autism knowledge and attitudes among the healthcare professionals in Lahore, Pakistan. BMC Pediatr 2011;11:107 